\title{
A case study on the potentials of card game assisted learning
}

Sung, Hui Chuan

National Taiwan Normal University, Taiwan, ROC (t10003@ntnu.edu.tw)

Ching, Gregory S.

Lunghwa University of Science and Technology, Taiwan, ROC (gregory_ching@yahoo.com)

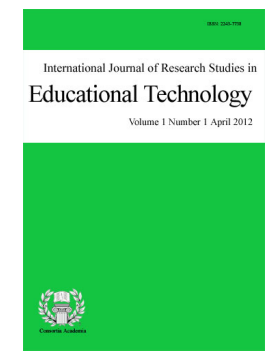

ISSN: $2243-7738$ Online ISSN: 2243-7746

\begin{abstract}
In the current world of today, English is undoubtedly the main language for global communication. For the business industry, almost more than $80 \%$ of the businesses in Taiwan are utilizing the Test of English as a Foreign Language (TOEFL), Test of English for International Communication (TOEIC) or General English Proficiency Test (GEPT) certifications as a basis for employment screening. Such emphasis in the importance of English language certification has actually opened up numerous opportunities for educational technology that help students learn better. This case study involves the use of a card game as a way to help develop the students TOEIC proficiencies. Results show that card game based language learning has indeed provided the possibility of improving the students' grades.
\end{abstract}

Keywords: language learning; board game; learning motivation; learning approaches; assessments 


\section{A case study on the potentials of card game assisted learning}

\section{Introduction}

Many scholars and educators have long been trying to include learning activities with the spirit of games. Such notions are expected to effectively increase the learning efficiency and interest of learners. When compared to traditional learning activities, educational technology in terms of games is considered to be more pleasant by majority of the students. Lepper and Cordova (1992) mentioned that in game playing students goes through a type of learning engagement. The situation actually refers to the phenomenon of intrinsic motivation and is composed of four sources: challenge, curiosity, control, and fantasy.

In game plays, most participants are volunteers in taking part of the game activities. Games are commonly held voluntarily with no force needed. Nevertheless, most traditional classroom student learners have passively participates in such learning activity and relies on outer factors to continue their learning. Students will tend favor active games over traditional learning in the classroom. Therefore, if we can effectively utilize designed learning activities (learning incorporated with games) the increased in interest of students' would be expected. With the high learning interest, students' knowledge learning ability would increase as well.

In Taiwan, within the paradigm of multiliteracies, the rise in popularity of the concept of English for Specific Purpose (ESP) language learning in English as a Foreign Language (EFL) countries, has also encouraged dramatic curricular changes. Currently, English is being regarded as the de-facto language in the areas of banking, commerce, trade, research, technology, and tourism (Tsai, 1998). As Taiwan engages more centrally as a player in the global economic stage (Mok, 2005; Zaharia \& Gilbert, 2005), the trend of using English as a medium of business transaction has become an increasingly important element for the education of Taiwan students. In its role as a global language, English has already become one of the most important academic and professional tools (Schutz, 2006). Therefore, it is quite important to find effective ways in combining current educational technology in teaching English to Taiwanese students. English is indeed the main language of global communication. While learning English, students usually have trouble memorizing the vocabularies. However, with the aid of interesting games to help students learn vocabularies. It would be beneficial for the teaching learning process. Game based learning is not only for the students to learn happily, but it also brings a sense of accomplishment. Hence, if games could be effectively drawn into the school learning environment, it will surely improve the existing learning method.

\section{Game based learning}

Students grow up under the influence of society and family that possessed various everyday life concepts. Such notion can always be the base on preliminary knowledge for learning scientific concepts and also provide reference for new concepts or the framework of a new knowledge. Accordingly, having more everyday life concepts with effective guides and tools do indeed help students learn regular scientific concepts. Thus it can be applied on subjects other than English vocabulary learning through the guidance of teachers to increase interactive learning.

A game is said to be an activity engaged in for diversion and fun (Game, 2011). It is mentioned that game based learning utilizes the concept of competitive exercises; wherein students compete with each other or to make or getting them to challenge themselves in order to motivate them to learn better. Games often have a fantasy element that engages players in a learning activity through a storyline. However, in order to create a truly educational game; educators needs to make sure that learning the material is essential to scoring and winning (Science Education Resource Center, 2008a).

The Science Education Resource Center (2008b) also described that for a game based learning to become 
A case study on the potentials of card game assisted learning

effective, some features (just like in a good lesson plan) should be available. Achievement; each lesson is based on objectives for students to achieve; such as new understanding and new skills to learn. Motivation; learning should be made around topics that are fundamentally interesting. Lessons can be made to connect with each other in a way that relates to students' actual needs. Lastly, assessment; these are feedback the students and teachers need to determine the level of improvement.

\section{Design}

This study is design as an action research. Action research has been used in many areas, where an understanding of complex social situations has been sought in order to improve the quality of life. Kurt Lewin; often cited as the originator of action research, used the methodology in his work with people affected by post-war social problems (McKernan, 1991). Action research approaches to educational research were adopted in the late $60 \mathrm{~s}$ and early $70 \mathrm{~s}$ by the teacher-researcher movement in the secondary education sector. Its combination of action and research had contributed to the attraction to researchers, teachers, and the academic community alike (Cohen, Manion, \& Morrison, 2007).

Action researchers are accountable in that they aim to make their learning process and its results public, both to each other and to other interested practitioners, using accessible terminology. Their practice is self-evaluated in that the reflective and analytical insights of the researcher- practitioners themselves form the basis of the developmental process. Action research is participative in that those involved contribute equally to the inquiry, and collaborative in that the researcher is not an expert doing research from an external perspective, but a partner working with and for those affected by the problem and the way in which it is tackled.

In addition, this research is designed as a case study, wherein the primary objective is to investigate a contemporary phenomenon within its real-life context; when the boundaries between phenomenon and context are not clearly evident; and in which multiple sources of evidence are used (Yin, 1984, p. 23). Furthermore, Merriam (1998) views a case as an individual, a program, a class or students, a school, or a community. She fashions the distinctiveness of case studies as particularistic because of the focus on one social unit; descriptive because they result in a rich thick portrait; and heuristic because case studies sharpen readers' understanding while leading to a new meanings.

\subsection{Case selection}

For the current study, the specific case chosen is to understand the benefits and challenges of developing a card game assisted learning project. Study participants are the eight (8) volunteer Applied Foreign Languages (AFL) Senior $\left(4^{\text {th }}\right.$ year) Students of a Science and Technology University in the Northern area in Taiwan.

\subsection{Objectives}

To determine the benefits and challenges of developing a card game assisted English language learning strategy. Furthermore, the study shall be able to contribute to the enhancement of the educational technology in terms of card game design. In the current world of fully dependent on information technology, the concept of non-digital learning strategy should be encouraged.

\subsection{Data gathered and analysis method}

Game based activities and tools used in this research are mentioned below: The game based learning activities used were based on 6 sets of English publications which included the categories of both vocabularies and reading articles. The flashcards were made by the reference of the publications. The front side showed the vocabularies and the definition and phonetic symbols were showed in the opposite. For the data analyses procedures, data gathered are separated into quantitative game scores, pre/post academic grades and qualitative reflection write-ups by the participants. For the qualitative reflection write-ups, these were analyzed using the 
Sung, H. C. \& Ching, G. S.

Miles and Huberman (1994) method for generating meaning.

\subsection{Research process}

This initial part of the study was accomplished primarily by two of participants who were tasked for the card game creation. The research process is achieved with the following steps: Background literature reviews, designing the game play, actual game creation, action research cycles 1 to 5 , gathering of scores in each of the game cycles, gathering of pre/post academic grades, writing reflection logs, data analysis and implications, and lastly, the conclusion and recommendations section. In addition, during each of the action research cycles wherein student participants played the game based TOEIC learning strategy. Slight revisions on the game-playing rules were done to improve the learning process. Reflections were then noted on the end of the three month period.

\subsection{Game card creation and rules}

The game cards are created using Bristol boards, printing on the back and front of A4 size. The vocabularies were collected from a TOEIC dictionary, and were selected from the moderate difficult to difficult lists. The cards were printed out and cut, ensuring the size to be uniform. The game play was design and slightly revised in order to improve the learning process. The following are the finalized game playing rules:

1. A total of 60 cards were selected from the stack and distributed to each of the players. A total of 15 cards per players. (A maximum of four players per game)

2. Each of the cards has the meaning or definition, while the other side contains the phonetic pronunciation of the word.

3. Each player should have 5 cards on their hand.

4. Game-play is like playing a poker.

The game playing is as follows:

The players take turn setting one card down and hoping that no one is able to know the vocabulary. If a player guesses the right vocabulary, the player will get a point. At all time, all players must have 5 cards on their hand. After all the cards on the deck has been used up. The players will now discuss the meaning of the cards that were not able to answer. In such ways the players will eventually learn all the vocabulary in the deck.

\section{Results and discussions}

The primary objective of this study is to examine the implications of a game based learning activity with regards to the students' English language development. Similarly, this study also aims to determine the implications of game based learning activity with regards to the students' English language development. The results of this study will be presented in two parts. The first part will be qualitative reflective logs of the student participants. While the second part shall be the quantitative pre/post academic grades comparison, which depicts the students' academic grade differences before and after participation in the game based learning activity.

\subsection{Implications of a game based learning activity}

After the four months participation in the game based TOEIC activity, student participants are asked to write a reflective log indicating their comments and perceived advantages and disadvantages regarding such activity. The following sections shall consist of the various reflection logs provided by the student participants. Furthermore, these shall be concluded with a summarized of the various re-emerging themes using the Miles and Huberman (1994) method for generating meaning. 
A case study on the potentials of card game assisted learning

Game based learning helps motivate students - Students mentioned that they are more motivated than compared to the usual learning environment. Game based learning can be used as a way to reinforce the normal learning environment. Through the use of a more familiar strategy that the students are used to, game based learning (non-digital) is a path that most educators have already forgotten since the advent of the information technology.

While playing the game, I can feel a sense of excitement. - Student $\mathrm{F}$

This is more interesting than normal lectures. - Student C

Learning by doing - Students have repeated mentioned that while they were deciding on which words (vocabularies) from the TOEIC dictionary to include within the game. Students unknowingly have already started to learn the words. This is actually the closely related to the concept of learning by doing of Dewey (1903). This is to say that the students experience in selecting (creating) the card game have benefited their vocabulary depth.

I know it. I think I pick up a lot of the words when I was selecting the words. - Student A

In doing this card game, I learn that I can be more comfortable with the vocabulary. Before I

hate to read the books, now I am okay. - Student B

Repeated tasks reinforced learning - A concept of practice makes perfect. In most occasions, observing a task being performed or attempted by someone else often accelerates human learning (Bentivegna, 2005). Beyond this, the notion of personally being involved with the task also reinforces learning. Such concept involved the combination of knowledge taught and authentic tasks to reinforce the learning process; a process also known as experiential learning (Kolb, 1984). Furthermore, Kolb (1984) also mentioned that "learning is the process whereby knowledge is created through the transformation of experience" (p. 38). This theory is also applied into the professional field as in the concept of work-integrated learning theories, such as the integration of employment-oriented work experiences into the education curriculum; is considered appropriate for developing skills in higher education, particularly in business schools (Miettinen, 2000).

After playing for awhile, my scores have gone up. The vocabulary seems so familiar to me now. - Student E

The more I play, the more I learn. I think this is helpful for me. - Student $\mathrm{H}$

In addition, students' game-playing scores were also tabulated. Table 1 shows that after playing six times, the players already improved from a low points of 11 to a perfect points of 60. Such results show that students can learn 60 vocabularies by playing (or discussing) six times (a total of 12 days).

\subsection{Implications on the students' language learning development}

With regards to the student participants' implications on the game based TOEIC learning activity, the pre and post academic grades in four subjects were gathered, tabulated, and analyzed with results are as follows. Table 2 shows the different subject and their corresponding pre/post grades, in addition, the grade difference (with positive value indicating an increased in grade, while a negative value indicating a decreased in grade) and the mean (average) difference. Of the four academic subject grades given, the highest mean difference with a positive value of 10.00 is the English conversation. All of the students got increased grades in the four subject areas. Such result indicates that the game based TOEIC learning strategy is quite successful in maintaining and increasing the students' grades. 


\section{Table 1}

Game play scores

\begin{tabular}{ccccccc}
\hline \multirow{2}{*}{ Students } & \multicolumn{9}{c}{ Scores } \\
\cline { 2 - 7 } & Session 1 & Session 2 & Session 3 & Session 4 & Session 5 & Session 6 \\
\hline A & 18 & 22 & 35 & 42 & 55 & 60 \\
B & 13 & 19 & 32 & 40 & 52 & 60 \\
C & 16 & 19 & 33 & 43 & 51 & 60 \\
D & 15 & 20 & 39 & 45 & 55 & 60 \\
E & 11 & 16 & 33 & 47 & 53 & 58 \\
F & 16 & 19 & 30 & 46 & 56 & 60 \\
G & 17 & 18 & 32 & 44 & 52 & 60 \\
H & 13 & 14 & 29 & 40 & 49 & 58 \\
I & 12 & 13 & 29 & 40 & 48 & 57 \\
J & 14 & 15 & 33 & 44 & 52 & 60 \\
\hline
\end{tabular}

Table 2

Academic grades increased/decreased

\begin{tabular}{lc}
\hline \multicolumn{1}{c}{ Subject } & Average grade increased/decreased \\
\hline English Listening and Speaking & 8.50 \\
English Conversation & 10.00 \\
English Writing - Basic & 8.00 \\
Public Speaking - Advanced & 7.00 \\
\hline
\end{tabular}

\section{Conclusions}

Recently, much concern regarding the students English language proficiency is observed. With the increased emphasis placed on TOEIC examination, many students try to study and take the exam. In essence, this study will be able to provide various important tips for students who want to take the TOEIC examination in a fun way. This action research is done by using a game based TOEIC learning activity. Participants are ten volunteer students from the AFL department of a Science and Technology University in Taiwan. Students meet bi-monthly for four months to play the game based TOEIC learning activity. Data collected include bi-monthly meetings logs, game play scores, observations, reflection logs, and pre/post academic grades. Results indicate that by just playing the game based activity for six times the students can learn up to 60 different vocabularies. In addition, after playing the game based activity for four months, significant improvement on four academic subjects were observed, namely: English Listening and Speaking, English Conversation, English Writing - Basic, and Public Speaking - Advanced. In essence, a non-threatening activity used towards the improvement of the students' TOEIC vocabulary power is helpful to develop the students English language competencies.

NOTE: This paper is the result of an undergraduate project undertaken in Lunghwa University of Science and Technology. 


\section{References:}

Bentivegna, D. (2005). Learning from observation using primitives. Retrieved November 28, 2011, from http://www.cns.atr.jp/ dbent/

Cohen, L., Manion, L., \& Morrison, K. (2007). Research methods in education. New York: Routledge.

Dewey, J. (1903). Democracy in Education. The Elementary School Teacher, 4(4), 193-204. $<$ http://dx.doi.org/10.1086/453309>

Game. (2011). Merriam-Webster.com. Retrieved November 30, 2011, from http://www.merriam-webster.com/dictionary/game

Kolb, D. A. (1984). Experiential learning. Experience as the source of learning and Development. Englewood Cliffs, NJ: Prentice Hall.

Lepper, M. R., \& Cordova, D. I. (1992). A desire to be taught: Instructional consequences of intrinsic motivation. Motivation and Emotion, 16, 187-208. <http://dx.doi.org/10.1007/BF00991651>

McKernan, J. (1991). Curriculum action research. London: Kogan Page.

Merriam, S. B. (1998). Qualitative research and case study applications in education. San Francisco: Jossey Bass.

Miettinen, R. (2000). The concept of experiential learning and John Dewey's theory of reflective thought and action. International Journal of Lifelong Education, 19(1), 54-72. <http://dx.doi.org/10.1080/026013700293458>

Miles, M., \& Huberman, M. (1994). Qualitative data analysis (2nd ed.). Beverly Hills, CA: Sage.

Mok, K. H. (2005). Fostering entrepreneurship: Changing role of government and higher education governance in Hong Kong. Research Policy, 34, 537-554. <http://dx.doi.org/10.1016/j.respol.2005.03.003>

Schutz, R. (2006). English made in Brazil [Electronic Version]. Retrieved March 22, 2006, from http://frankherles.wordpress.com/2007/11/27/the-history-of-the-english-language/

Science Education Resource Center. (2008a). Game based learning. Retrieved November 10, 2011, from http://serc.carleton.edu/introgeo/games/

Science Education Resource Center. (2008b). What is GBL? Retrieved November 10, 2011, from http://serc.carleton.edu/introgeo/games/whatis.html

Tsai, S. (1998). The effects of cooperative learning on teaching English as a foreign language to senior high school students. Unpublished Masteral thesis, National Kaohsiung Normal University, Kaohsiung, Taiwan.

Yin, R. K. (1984). Case study research: Design and methods. Newbury Park, CA: Sage.

Zaharia, E. S., \& Gilbert, E. (2005). The entrepreneurial university in the knowledge society. Higher Education in Europe, 31(1), 31-40. <http://dx.doi.org/10.1080/03797720500088038> 
Sung, H. C. \& Ching, G. S. 